\title{
Effect of Gd on microstructure and refinement performance of Al-5Ti-B alloy
}

\author{
*Dong-song Yin', Ning Zhang', Ke-ju Chen', **Yun-long Zhang' \\ 1. School of Materials Science and Engineering, Heilongjiang University of Science and Technology, Haerbin 150022, China \\ 2. School of Materials Science and Engineering, Jiamusi University, Jiamusi 154007, China
}

\begin{abstract}
Al-5Ti-B and Al-5Ti-B-Gd master alloy refiners were fabricated by fluorine salt casting method. The microstructure and phase constitution of the master alloys were investigated by scanning electron microscopy (SEM), transmission electron microscopy (TEM) and X-ray diffraction (XRD). The results show that Al-Ti-B alloy refiner consists of $\mathrm{Al}_{3} \mathrm{Ti}$ phase and $\mathrm{TiB}_{2}$ phase. After $\mathrm{Gd}$ is introduced into the intermediate alloy, $\mathrm{Ti}_{2} \mathrm{Al}_{20} \mathrm{Gd}_{\text {d }}$ phase appears in the alloy, the size of $\mathrm{Al}_{3} \mathrm{Ti}$ is significantly reduced, and Ti-Al-Gd phase is found in the edge of $\mathrm{Al}_{3} \mathrm{Ti}$ phase. At the same time, some independent Ti-Al-Gd phases appear in local areas, which are $\mathrm{Ti}_{2} \mathrm{Al}_{20} \mathrm{Gd}_{\text {d }}$ phase determined by micro-area electron diffraction analysis. Analysis and calculation results of the high-resolution images of the $\mathrm{Ti}_{2} \mathrm{Al}_{20} \mathrm{Gd} / \mathrm{Al}$ structure show that there is no other compound at the junction between the $\mathrm{Ti}_{2} \mathrm{Al}_{20} \mathrm{Gd}$ phase and $\mathrm{Al}$, and $\mathrm{Ti}_{2} \mathrm{Al}_{20} \mathrm{Gd}$ phase has a great difference in atomic space with the $\alpha-\mathrm{Al}$, which cannot be directly used as heterogeneous nucleus. But, after being decomposed in the aluminum melt, the $\mathrm{Ti}_{2} \mathrm{Al}_{20} \mathrm{Gd}$ phase can promote the refinement effect of the refiner. In the Al-Ti-B-Gd master alloy, there are many dispersed $\mathrm{Al}_{3} \mathrm{Ti}$ particles with a size of less than $1 \mu \mathrm{m}$, which can promote the Al-5Ti-B refining effect.
\end{abstract}

Key words: $\mathrm{Al}-5 \mathrm{Ti}-\mathrm{B}$ alloy refiner; $\mathrm{Al}_{3} \mathrm{Ti}$; rare earth $\mathrm{Gd} ; \mathrm{Ti}_{2} \mathrm{~A} 1_{20} \mathrm{Gd}$

CLC numbers: TG146.21

Document code: $\mathrm{A}$

Article ID: 1672-6421(2021)03-223-06

\section{Introduction}

Aluminum alloys have the advantages of low density, high specific strength, good ductility and easy recycling. As structural materials, they are widely applied in the fields of aerospace, automobiles, electronics and rail transportation. However, the coarse grain of as-cast aluminum alloy reduced the mechanical properties and significantly reduced the subsequent rolling properties. To solve this problem, the most common method in industry is to introduce Al-Ti-B refiner to obtain fine equiaxed grains, with the aim to improve the comprehensive mechanical properties and calendering ability of aluminum alloy ${ }^{[1-2]}$.

The synthetic method of Al-Ti-B grain refiner was mainly a fluoride salt method. However, the potassium fluoroaluminate, as by-product, is adulterated into the Al-

\section{*Dong-song Yin}

Male, born in 1974, Ph. D., Professor. His research interest mainly focuses on light alloys. To date, he has published 40 technical papers and 2 books, and holds 5 invention patents of China.

E-mail: dongsongyin@126.com

*Yun-long Zhang

E-mail: ylzhdr@126.com

Received: 2020-12-08; Accepted: 2021-03-25
Ti-B grain refiner, which reduces the purity of the AlTi-B grain refiner, and therefore, leads to a significant decrease in the mechanical properties and corrosion resistance of aluminum alloys. The most important is that the coarse needle-like and strip-like $\mathrm{Al}_{3} \mathrm{Ti}$ existing in the Al-Ti-B deteriorates its refining performance. Many researchers reported that the size and morphology of $\mathrm{Al}_{3} \mathrm{Ti}$ particles had obvious influence on the refining capacity of Al-Ti-B refiner ${ }^{[3]}$. Researchers adopted different strategies to control the size and morphology of $\mathrm{Al}_{3} \mathrm{Ti}$ particles, such as ultrasonic technology, mechanical or electromagnetic stirring, and so on. However, the action scope of ultrasonic method is narrow, and it is difficult to realize industrialization. Mechanical and electromagnetic stirring methods require special equipment, so the production cost is high. In addition, the oxidation inclusions are easy to be involved during the operation process, thus reducing the refining performance of Al-Ti-B refiner ${ }^{[4-5]}$.

The addition of rare earth elements to aluminum alloys has unique advantages. An appropriate amount of rare earth elements (La Ce Er Y, etc.) can purify the melt of Al-Ti-B alloy and significantly increase the long-term effectiveness of the refiner. Rare earth elements have a unique activity, which can significantly affect the morphology, size, and 
distribution of the second phase in the metal, and can also have a significant impact on the refining effect of the alloy refiner ${ }^{[1-3]}$. Reports showed that rare earth could refine $\mathrm{Al}_{3} \mathrm{Ti}$ phase and form $\mathrm{Ti}_{2} \mathrm{Al}_{20} \mathrm{Re}$ phase, which significantly improved the refining performance of alloy refiners ${ }^{[4-7]}$. However, there is a lack of in-depth research on the in-situ crystallographic diffraction analysis of $\mathrm{Ti}_{2} \mathrm{Al}_{20} \mathrm{Re}$ phase and the interface relationship between $\mathrm{Ti}_{2} \mathrm{Al}_{20} \mathrm{Re}$ and aluminum matrix, which will affect the judgment of the refining effect of $\mathrm{Ti}_{2} \mathrm{Al}_{20} \mathrm{Re}$ on aluminum alloy. Yin et al. ${ }^{[8]}$ found that Gd element can significantly improve the refinement effect of Al-5 Ti on Al-7Si alloy, but the mechanism of how $\mathrm{Gd}$ element affected the $\mathrm{Al}_{3} \mathrm{Ti}$ phase was unclear.

In this study, Al-5Ti-B refiner was prepared by fluoride salt method. The microstructure of the alloy after adding Gd was observed. The influence of rare earth Gd on heterogeneous nucleation particles in the refiner was discussed. It would provide a reference for the research and development of AlTi-B refiner containing rare earth elements.

\section{Experimental procedure}

Industrial double zero aluminum ( $\geq 99.70 \%$ ), titanium powder $(\geq 99.50 \%)$ and potassium fluoborate $(\geq 98.00 \%)$ were utilized as raw materials, and rare earth Gd was added in Al-30\%Gd intermediate alloy. The aluminum ingot was put into a graphite crucible (a well-type resistance furnace), and heated to $(850 \pm 5){ }^{\circ} \mathrm{C}$. After the aluminum melt was completely melted, titanium powder and $\mathrm{KBF}_{4}$ which have been crushed into pieces were added into the melt using a graphite bell jar. After the reaction was accomplished, Al-30\%Gd master alloy was added, then slag was removed with stirring, and then cooled to $800{ }^{\circ} \mathrm{C}$. Finally, it was cast into a metal mold to obtain the aluminum alloy refiner containing rare earth elements. The metal mold had an inner diameter of $50 \mathrm{~mm}$ to obtain a cylindrical refiner with a size of $\Phi 50 \mathrm{~mm} \times 50 \mathrm{~mm}$. The process was carried out under special covering agent, degassing agent and refining agent for aluminum alloys.

Block samples of $10 \mathrm{~mm} \times 10 \mathrm{~mm} \times 10 \mathrm{~mm}$ were cut from the center of the cylindrical Al-5Ti-1B and Al-5Ti-1B-1Gd master alloy refiners. Part of the sample was cut off, ground and polished, then eroded with reagent $\left(95.5 \mathrm{~mL} \mathrm{H}_{2} \mathrm{O}+0.5 \mathrm{~mL}\right.$ $\mathrm{HF}$ ). The phase constitution of the alloy was analyzed using a Bruker DS Advance X-ray diffractometer. The microstructure was observed using a QUAN200 scanning electron microscope (SEM), and the composition of the micro-area was analyzed using an energy dispersive analyzer (EDS). The morphology of solidified phase was analyzed using the FEI Talos field emission transmission electron microscopy (TEM).

\section{Results and discussion}

\subsection{Phase constitution}

Figure 1 shows the X-ray diffraction patterns of Al-Ti-B and Al-Ti-B-Gd master alloy refiners. It can be seen that the diffraction pattern of Al-Ti-B alloy refiners has not only many $\alpha$-Al diffraction peaks, but also $\mathrm{A}_{3} \mathrm{Ti}$ and $\mathrm{TiB}_{2}$ diffraction peaks.

The following reactions take place when titanium powder briquette and potassium fluoborate briquette are added at the same time to prepare Al-Ti-B:

$$
\begin{aligned}
& \mathrm{L} \rightarrow \mathrm{Al}+\mathrm{Al}_{3} \mathrm{Ti} \\
& 2 \mathrm{KBF}_{4}+3 \mathrm{Al} \rightarrow \mathrm{AlB}_{2}+2 \mathrm{KAlF}_{4} \\
& \mathrm{AlB}_{2}+\mathrm{Al}_{3} \mathrm{Ti} \rightarrow \mathrm{TiB}_{2}+4 \mathrm{Al}
\end{aligned}
$$

For Al-Ti-B-Gd master alloy, besides the above diffraction peaks, there is also a diffraction peak of $\mathrm{Ti}_{2} \mathrm{Al}_{20} \mathrm{Gd}$ phase. This is because the rare earth $\mathrm{Gd}$ elements react with $\mathrm{Al}_{3} \mathrm{Ti}$ when they are enriched to a certain concentration ${ }^{[7]}$.

$$
14 \mathrm{Al}+2 \mathrm{~A} 1_{3} \mathrm{Ti}+\mathrm{Gd} \leftrightharpoons \mathrm{Ti}_{2} \mathrm{Al}_{20} \mathrm{Gd}
$$
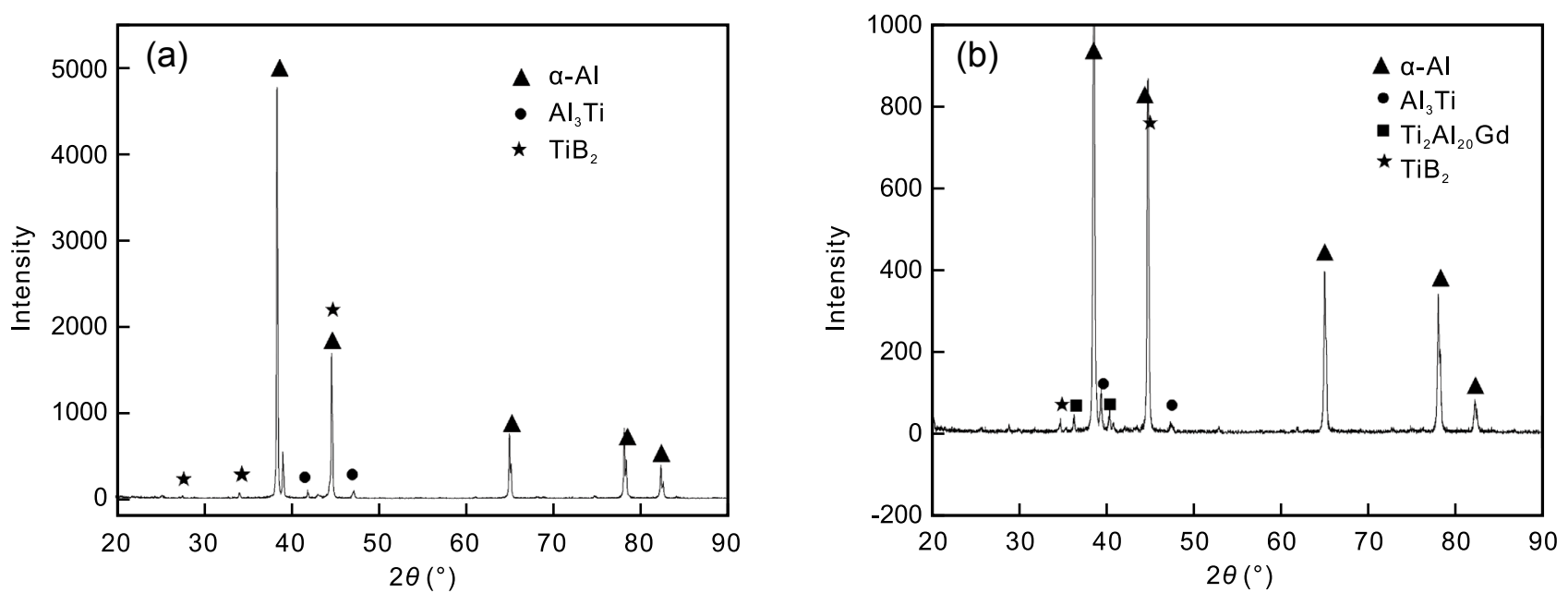

Fig. 1: X-ray diffraction patterns of Al-Ti-B (a) and Al-5Ti-B-Gd alloy (b) 


\subsection{Microstructure}

Figure 2 shows the SEM of Al-5Ti-B and Al-5Ti-B-Gd master alloys. It can be seen in Fig. 2(a) that there are coarse and irregularly shaped solid phases [such as Area A in Fig. 2(a)] distributed in the alloy matrix, and their sizes fluctuate within the range of 20-100 $\mu \mathrm{m}$. The results of energy spectrum analysis at Area A show that this phase is Al-Ti phase, and the molar ratio of $\mathrm{Al} / \mathrm{Ti}$ is close to $3: 1$ (Table 1). Combined with X-ray diffraction analysis and previous research ${ }^{[5-7]}$, this phase can be determined as $\mathrm{Al}_{3} \mathrm{Ti}$. After adding rare earth $\mathrm{Gd}$, as shown in Fig. 2(b), the solid phase is refined and distributes dispersively, with significant changes in morphology. As shown in the lower left corner of Fig. 2(b), there is a solidified structure with unique morphology, which is composed of Phase $\mathrm{C}$ with bright white edge contrast and Phase $\mathrm{B}$ with dark gray center contrast. According to energy spectrum analysis, Phase $\mathrm{C}$ is TiAlGd and Phase B is Al-Ti. The Ti/Al/Gd molar ratio of the TiAlGd phase is close to 2:20:1; the $\mathrm{Al} / \mathrm{Ti}$ molar ratio of Al-Ti phase is close to 3:1 (as shown in Table 1). Therefore, it is speculated that Phase $\mathrm{C}$ is $\mathrm{Ti}_{2} \mathrm{Al}_{20} \mathrm{Gd}$ and Phase $\mathrm{B}$ is $\mathrm{Al}_{3} \mathrm{Ti}$. This kind of structure has also been found when adding rare earth elements such as $\mathrm{Ce}$ and $\mathrm{La}$ to the Al-Ti-B alloy ${ }^{[5]}$. However, few reports can be found concerning the $\mathrm{Ti}_{2} \mathrm{Al}_{20} \mathrm{Gd}$ phase that is produced by adding Gd to Al-5Ti-B alloy. The in-situ analysis and verification on $\mathrm{Ti}_{2} \mathrm{~A} 1_{20} \mathrm{Gd}$ phase were carried out by electron diffraction as shown below.
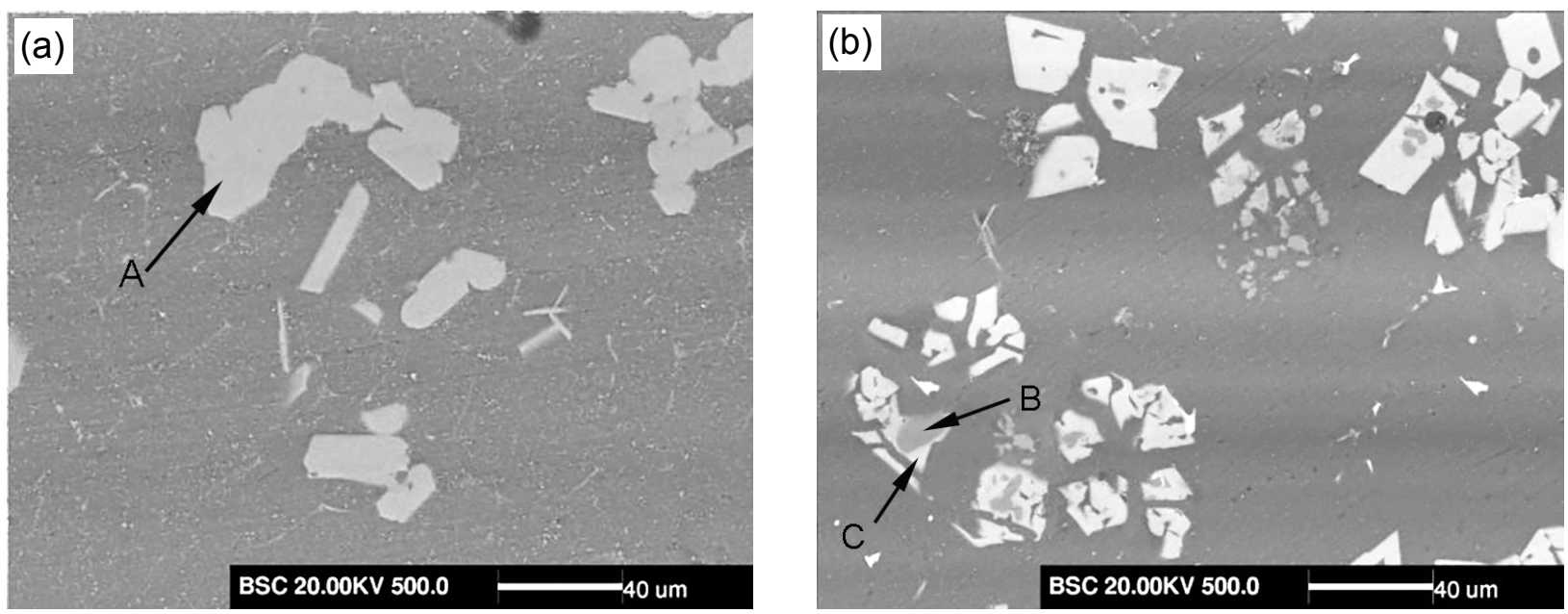

Fig. 2: SEM morphology of Al-5Ti-B and Al-5Ti-1B-Gd master alloy: (a) Al-5Ti-1B; (b) Al-5Ti-1B-Gd

Figure 3(a) shows the microscopic morphology of the Al-5Ti-B-Gd master alloy. There are two kinds of phases distributed in the alloy matrix, which are accompanied by each other, among which the long block phase in bright gray (Phase D) is Al-Ti, according to the energy spectrum analysis results shown in Table 1, and the dark gray phase (Phase E) is TiAl-Gd phase. Combined with XRD results, it was considered that Phase $\mathrm{D}$ is $\mathrm{Al}_{3}$ Ti phase and Phase $\mathrm{E}$ is $\mathrm{Ti}_{2} \mathrm{Al}_{20} \mathrm{Gd}$ phase. There are no voids, cracks, and other compound layers at the interface between the above two phases.

The electron diffraction analysis of Point $\mathrm{E}$ is carried out and the calibration results of the electron diffraction spots are shown in Fig. 3(b), which indicates that Phase $\mathrm{E}$ is $\mathrm{Ti}_{2} \mathrm{~A}_{20} \mathrm{Gd}$. The calculated lattice constant "a" of this phase is 14.60 , which is very close to the lattice constant of $\mathrm{Ti}_{2} \mathrm{Al}_{20} \mathrm{Gd}$ phase. The above results confirm the existence of $\mathrm{Ti}_{2} \mathrm{Al}_{20} \mathrm{Gd}$ phase around $\mathrm{Al}_{3}$ Ti phase according to the crystallographic point of view, which is of great significance.
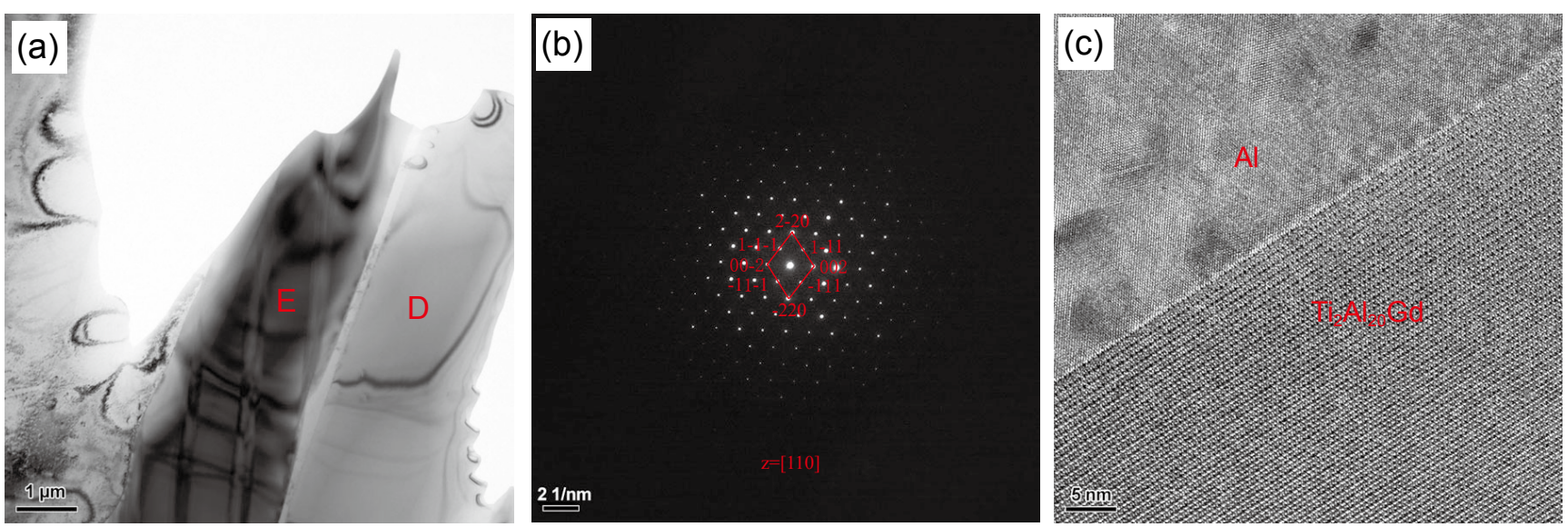

Fig. 3: TEM morphology and electron diffraction analysis of AI-5Ti-1B-Gd master alloy: (a) TEM image; (b) electron diffraction analysis; (c) $\mathrm{Ti}_{2} \mathrm{Al}_{20} \mathrm{Gd} / \mathrm{Al}$ high resolution image 
Table 1: EDS analysis results of Al-5Ti-1B and Al-5Ti-1B-Gd master alloys (at.\%)

\begin{tabular}{ccccc} 
Phase & Al & Ti & B & Gd \\
A & 73.64 & 26.36 & & \\
B & 73.05 & 26.95 & & \\
C & 86.40798 & 9.20516 & & 4.38686 \\
D & 77.51385 & 22.48615 & & \\
E & 87.48280 & 8.26016 & & 4.25705 \\
F & 0.91131 & 21.29957 & 77.78913 & \\
G & 75.42526 & 24.57474 & & \\
\hline & & & & \\
\hline
\end{tabular}

Figure 3(c) shows a two-dimensional atomic high-resolution photograph of $\alpha-\mathrm{Al}$ and $\mathrm{Ti}_{2} \mathrm{~A} 1_{20} \mathrm{Gd}$. After measurement, the singlerow atomic spacings of $\alpha-\mathrm{Al}$ and $\mathrm{Ti}_{2} \mathrm{Al}_{20} \mathrm{Gd}$ are $0.2744 \mathrm{~nm}$ and $0.9882 \mathrm{~nm}$, respectively, and their interface is in a non-coherent state with a great mismatch degree. Therefore, it can be judged that $\mathrm{Ti}_{2} \mathrm{Al}_{20} \mathrm{Gd}$ cannot be directly used as heterogeneous nuclei of $\alpha$-Al.

It can be seen from the above results that $\mathrm{Ti}_{2} \mathrm{Al}_{20} \mathrm{Gd}$ phase is easy to appear at the edge of $\mathrm{Al}_{3} \mathrm{Ti}$, and the size of $\mathrm{Ti}_{2} \mathrm{Al}_{20} \mathrm{Gd}$ at the edge of $\mathrm{Al}_{3} \mathrm{Ti}$ in different regions is quite different. The reason is that rare earth elements belong to surface active substances and their solid solubility in aluminum melt is extremely low, so they easily aggregate on the adsorption phase interface ${ }^{[10]}$. With the enrichment of $\mathrm{Gd}$ element, $\mathrm{Ti}_{2} \mathrm{~A} 1_{20} \mathrm{Gd}$ phase gradually forms and grows, so $\mathrm{Ti}$ atoms and $\mathrm{Al}$ atoms grow from two sources: one source is diffused from aluminum alloy melt, the other is obtained by consuming $\mathrm{Al}_{3} \mathrm{Ti}$ phase. The diffusion and enrichment of $\mathrm{Gd}$ element around $\mathrm{Al}_{3} \mathrm{Ti}$ creates vital conditions for the nucleation and growth of $\mathrm{Ti}_{2} \mathrm{Al}_{20} \mathrm{Gd}$. The enrichment degree directly affects the relative size between $\mathrm{Ti}_{2} \mathrm{Al}_{20} \mathrm{Gd}$ and $\mathrm{Al}_{3} \mathrm{Ti}$. When the growth of $\mathrm{Ti}_{2} \mathrm{Al}_{20} \mathrm{Gd}$ uses up the $\mathrm{Al}$ and $\mathrm{Ti}$ atoms in $\mathrm{Al}_{3} \mathrm{Ti}$, a single $\mathrm{Ti}_{2} \mathrm{Al}_{20} \mathrm{Gd}$ phase appears.

Figure 4(a) shows the fine particle phases distributed in Al5Ti-B-Gd. It can be found that the hexagonal particle phase $\mathrm{F}$ has a size ranging from $50 \mathrm{~nm}$ to $200 \mathrm{~nm}$. According to the energy spectrum analysis, this phase mainly contains Ti and B elements [Fig. 4(b)], which can be confirmed as a boride. Its morphology is very similar to that of $\mathrm{TiB}_{2}$ phase in the matrix of Al-5Ti-B alloy prepared by the fluorine salt method reported in the literature ${ }^{[11,12]}$. By EDS and XRD analysis (Fig. 1 and Table 1), combined with previous studies, it is speculated to be $\mathrm{TiB}_{2}$ phase. Generally, Al-5Ti-B master alloy (by fluoride salt method) would have $\mathrm{TiB}_{2}$ agglomeration phenomenon, that is, $\mathrm{TiB}_{2}$ phase with coral agglomeration, which decreases the refining effect of the master alloy on the corresponding aluminum alloy ${ }^{[11,12,13]}$. After the addition of rare earth $\mathrm{Gd}$, this tendency is obviously suppressed, which may be due to that the $\mathrm{Gd}$ atoms tend to converge at the interface front of $\mathrm{TiB}_{2}$ phase, hindering the agglomeration of $\mathrm{TiB}_{2}$ phase. $\mathrm{TiB}_{2}$ is a more stable phase in $\mathrm{Al}-\mathrm{Ti}-\mathrm{B}$ than $\mathrm{Al}_{3} \mathrm{Ti}$, which does not react with rare earths ${ }^{[14,15]}$. Phase $\mathrm{G}$ is strip-shaped, containing $\mathrm{Al}$ and Ti elements [Fig. 4(c)] with a molar ratio of $\mathrm{Al} / \mathrm{Ti}$ close to 3:1 (Table 1) from the energy spectrum analysis, so, it is $\mathrm{Al}_{3} \mathrm{Ti}$ phase. It did not grow up during the solidification of Al-5Ti-B.
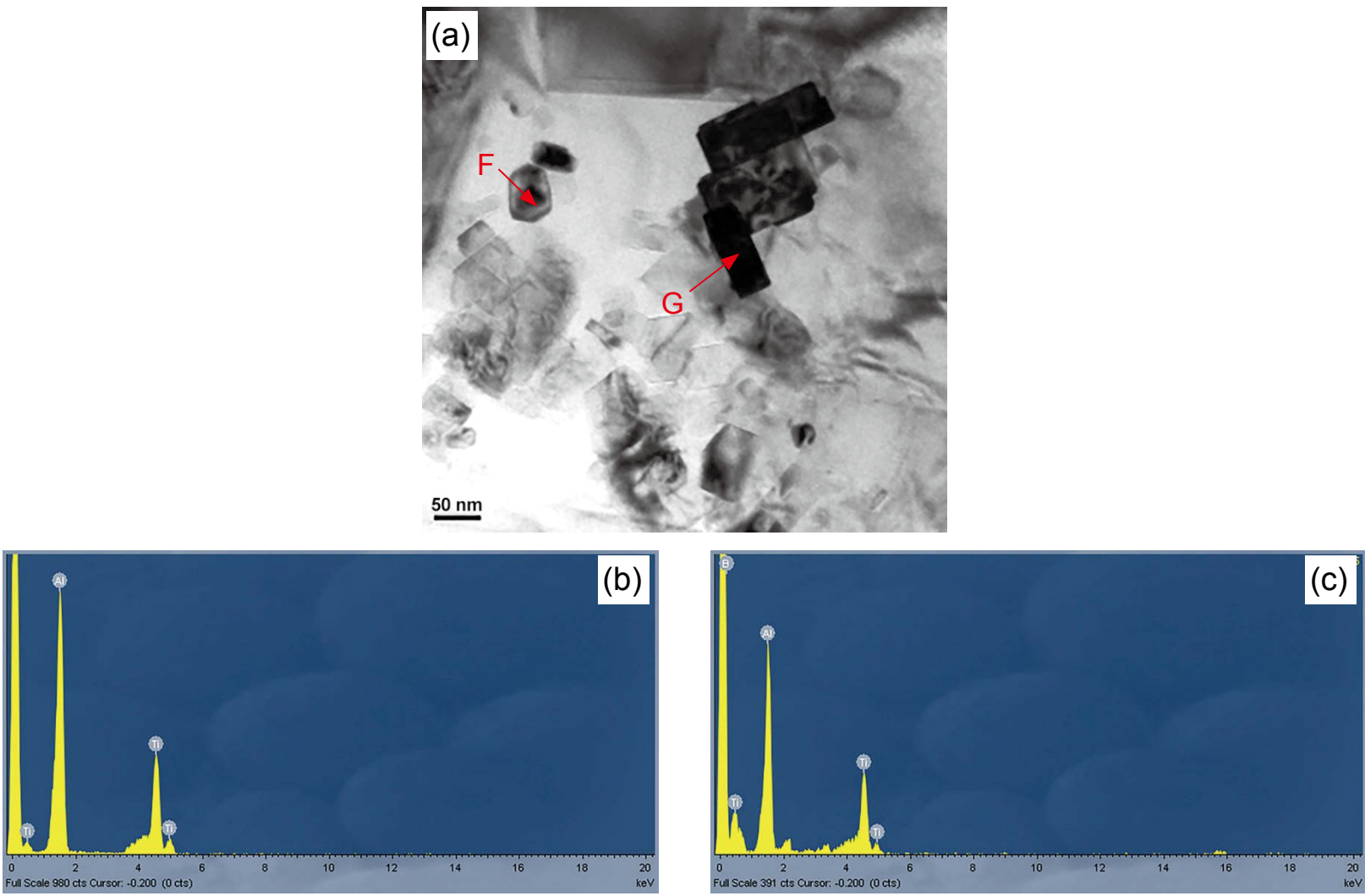

Fig. 4: Morphology and energy spectrum analysis of particle phase in Al-5Ti-B-Gd alloy: (a) particle phase morphology in Al-5Ti-B-Gd alloy; (b) Phase F energy spectrum analysis diagram; (c) Phase G energy spectrum analysis diagram 


\subsection{Refinement mechanism}

This study shows that rare earth Gd can significantly refine $\mathrm{Al}_{3} \mathrm{Ti}$ and cause $\mathrm{Al}_{3} \mathrm{Ti}$ to be equiaxed, which is one of the main reasons for improving the refining effect of Al-5Ti-B master alloy. According to the phase diagram of Al-Ti binary alloy ${ }^{[16]}$, when Ti content is $0.15 \%$ and temperature is $665^{\circ} \mathrm{C}$, peritectic reaction occurs as follows: $\mathrm{L}+\mathrm{Al}_{3} \mathrm{Ti} \rightarrow \alpha-\mathrm{Al}$. $\mathrm{Al}_{3} \mathrm{Ti}$ is a heterogeneous nucleus of $\alpha-\mathrm{Al}$, which plays a role in refining aluminum alloy. In fact, the final grain size of aluminum alloy is determined by the solute constraint of crystal nucleus and grain growth ${ }^{[16]}$, and the average grain size can be described as:

$$
D=a+b / Q^{[17]}
$$

where $a$ and $b$ are constants and $Q$ is a growth limiting factor used to measure the influence of solute on grain size when the interaction between solutes is not considered:

$$
Q=C_{0} m(k-1)^{[17]}
$$

where $C_{0}$ is the solute concentration in the melt, $m$ is the slope of liquidus, $k$ is the equilibrium partition coefficient. The $Q$ value of large flaky $\mathrm{Al}_{3} \mathrm{Ti}$ particles is smaller than that of fine flaky $\mathrm{Al}_{3} \mathrm{Ti}$ particles, therefore, it can be determined that fine equiaxed $\mathrm{Al}_{3} \mathrm{Ti}$ particles have a better refining effect on $\alpha$-Al than large flaky $\mathrm{Al}_{3}$ Ti particles ${ }^{[17]}$.

After adding Gd element into Al-Ti-B master alloy, the size of $\mathrm{Al}_{3} \mathrm{Ti}$ particles is significantly reduced ${ }^{[4-7]}$. The possible reasons are summarized below: first, the enrichment of rare earth $\mathrm{Gd}$ atoms on the surface of $\mathrm{Al}_{3} \mathrm{Ti}$ particles hinders the growth of $\mathrm{Al}_{3} \mathrm{Ti}$ particles, promotes the dispersion of $\mathrm{Al}_{3} \mathrm{Ti}$ particles and prevents their aggregation ${ }^{[5,6]}$; second, when $\mathrm{Gd}$ atoms are highly enriched, $\mathrm{Ti}_{2} \mathrm{Al}_{20} \mathrm{Gd}$ phase would form at the edge of $\mathrm{Al}_{3} \mathrm{Ti}$ particles, then the $\mathrm{Ti}_{2} \mathrm{Al}_{20} \mathrm{Gd}$ phase consumes $\mathrm{Ti}$ atoms in $\mathrm{Al}_{3} \mathrm{Ti}$, thus, $\mathrm{Al}_{3}$ Ti particles diminish constantly.

Thermodynamically, the $\mathrm{Ti}_{2} \mathrm{Al}_{20} \mathrm{Gd}$ phase is unstable. At the high temperature, the reaction of $\mathrm{Ti}_{2} \mathrm{Al}_{20} \mathrm{Gd} \leftrightharpoons$ $14 \mathrm{Al}+2 \mathrm{~A} 1_{3} \mathrm{Ti}+\mathrm{Gd}$ occurs and releases rare earth element $\mathrm{Gd}$. Gd combined with the active contacts on the second phase particles to form a "rare earth film", and the free energy of particles is reduced, so that the particles can exist in the solution for a longer time to play the role of heterogeneous nucleus and thus the refiner has a long-term refinement effect. In addition, the existence of rare earth element film hinders the aggregation and growth of second phase particles, further promoting the refinement ability of refiners ${ }^{[18]}$. Some rare earth atoms would be released from the rare earth film, although they are not enough to form a compound with the aluminum matrix, they can be concentrated at the boundary between grains and dendrites and play a role in refining grains and dendrites.

In the aluminum alloy, the refining effect of $\mathrm{TiB}_{2}$ particles alone on $\alpha-\mathrm{Al}$ is not obvious. This is because the interface energy of $\mathrm{Al} / \mathrm{TiB}_{2}$ produced by heterogeneous nucleation of $\alpha-\mathrm{Al}$ on $\mathrm{TiB}_{2}$ particles is greater than the liquid-solid interface energy as $\alpha-\mathrm{Al}$ nucleates directly from $\mathrm{Al}$ melt when aluminum alloy solidifies, so, $\mathrm{TiB}_{2}$ particles cannot act as the effective heterogeneous nucleus of $\alpha-\mathrm{Al}^{[19]}$. However, when $\mathrm{Al}_{3}$ Ti particles appear, i.e., using Al-5Ti-B as a refiner of aluminum alloy, $\mathrm{TiB}_{2}$ particles interact with $\mathrm{Al}_{3} \mathrm{Ti}$ particles to refine aluminum alloy, and the $\mathrm{Ti}$ from $\mathrm{Al}_{3} \mathrm{Ti}$ phase spontaneously enriches on the surface of $\mathrm{TiB}_{2}$ particles. This can provide a sufficiently high interface chemical potential to make the interface energy between the $\mathrm{TiB}_{2}$ particles and the surrounding liquid phase drop below the liquid-solid interface energy of $\mathrm{Al}$, thus stimulating the nucleation potential of $\mathrm{TiB}_{2}$ particles and causing $\alpha$-Al to produce an effective heterogeneous nucleus ${ }^{[18]}$. In the preparation of Al-5Ti-B by fluoride salt reaction, the aggregation of $\mathrm{TiB}_{2}$ phase occurs, which would reduce the refining effect of Al-5Ti-B. However, after adding $\mathrm{Gd}$, the aggregation of $\mathrm{TiB}_{2}$ phase was not found under transmission electron microscope. This may be due to the enrichment of rare earth elements at the front edge of the phase interface during the solidification of $\alpha-\mathrm{Al}$, which promotes the dispersion of $\mathrm{TiB}_{2}$ phase.

\section{Conclusions}

The effects of the introduction of rare earth element Gd on microstructure and refinement performance of Al-Ti-B alloy on aluminum alloy were investigated. The following conclusions can be obtained:

(1) In the Al-5Ti-B refiner prepared by conventional fluorine salt method, there is a thick $\mathrm{Al}_{3} \mathrm{Ti}$ phase on the matrix. After adding $1.0 \mathrm{wt} . \% \mathrm{Gd}, \mathrm{Al}_{3} \mathrm{Ti}$ phase is refined, which improves the refining performance of Al-5Ti-B alloy.

(2) When $1.0 \mathrm{wt} . \% \mathrm{Gd}$ is added to the Al-5Ti-B alloy refiner, $\mathrm{Ti}_{2} \mathrm{Al}_{20} \mathrm{Gd}$ phase appears at the edge of part of $\mathrm{Al}_{3} \mathrm{Ti}$ phase, and there is no compound layer at the interface between $\mathrm{Ti}_{2} \mathrm{Al}_{20} \mathrm{Gd}$ phase and aluminum matrix, and the lattice mismatch degree between $\mathrm{Ti}_{2} \mathrm{Al}_{20} \mathrm{Gd}$ phase and aluminum matrix is quite great, so $\mathrm{Ti}_{2} \mathrm{Al}_{20} \mathrm{Gd}$ phase cannot be used as heterogeneous nuclei of $\alpha$-Al. However, when $\mathrm{Ti}_{2} \mathrm{Al}_{20} \mathrm{Gd}$ phase is decomposed into $\mathrm{Al}_{3} \mathrm{Ti}$ phase and $\mathrm{Gd}$ element in aluminum melt, the refining performance of the refiner can be significantly improved.

(3) There are a great number of $\mathrm{TiB}_{2}$ particles smaller than $1 \mu \mathrm{m}$ dispersedly distributed in the Al-5Ti-B-Gd refiner. These particles can become effective heterogeneous nuclei and promote the refinement effect of the refiner.

\section{References}

[1] $X u X X$, Feng $Y T$, Fan $H$, et al. The grain refinement of 1070 alloy by different Al-Ti-B mater alloys and its influence on the electrical conductivity. Results in Physics, 2019, 14(9): 10241030.

[2] Matveev A, Zhukov I, Ziatdinov M, et al. Planetary milling and self-propagating high-temperature synthesis of $\mathrm{Al}_{-} \mathrm{TiB}_{2}$ composites. Materials, 2020, 13(5): 1050-1058.

[3] Jia Y W, Huang H J, Fu Y N, et al. An in-situ investigation of the solute suppressed nucleation zone in an $\mathrm{Al}-15 \mathrm{wt} . \% \mathrm{Cu}$ alloy Inoculated by Al-Ti-B. Scripta Materialia, 2019, 167: 6-10.

[4] Ding W W, Zhao X Y, Chen T L, et al. Effect of rare earth $Y$ and Al-Ti-B master alloy on the microstructure and mechanical properties of 6063 aluminum alloy. Journal of Alloys and Compounds, 2020, 830(25): 154-160. 
[5] Wang X J, Xu C, Muhammad A, et al. Effects of Al-Ti-B-RE grain refiner on microstructure and mechanical properties of Al7.0Si-0.55Mg alloy. Transactions of Nonferrous Metals Society of China, 2014, 24(7): 2244-2250.

[6] Wang Z J, Si N C. Effect of the morphology and distribution of the second phases of Al-Ti-B-RE master alloys on refining commercially pure aluminum. Rare Metal Materials and Engineering, 2015, 44(6): 1494-1499. (In Chinese)

[7] Ma T F, Chen Z Y, Nie Z R, et al. Microstructure of Al-Ti-BEr refiner and its grain refining performance. Journal of Rare Earths, 2013, 31(6): 622-670.

[8] Yin D S, Zhao J T, Zhang Z K. Effect of Mg-30\% Gd on dimensions distribution of $\mathrm{TiAl}_{3}$ particles in $\mathrm{Al}-5 \mathrm{Ti}$ alloys. Foundry Equipment and Technology, 2015 (4): 22-24. (In Chinese)

[9] Birol Y. Production of Al-Ti-B master alloys from Ti sponge and $\mathrm{KBF}_{4}$. Journal of Alloys and Compounds, 2007, 440(1-2): 108112.

[10] Yang M S, Wang Z F. Investigation of intermetallic compound formed from rapid solidification of Al-Ti-RE alloy. Journal of Rare Earths, 2004, 22(2): 311-314.

[11] Jia Y W, Wang S C, Shu D. Grain size prediction and investigation of 7055 aluminum alloy inoculated by Al-5Ti-1B master alloy. Journal of Alloys and Compounds, 2020, 821: 153504.

[12] Nie J F, Liu X F, Ma X G. Influence of trace boron on the morphology of titanium carbide in an Al-Ti-C-B master alloy. Journal of Alloys and Compounds, 2010, 491(1-2): 113-117.
[13] Li P T, Li Y G, Nie J F, et al. Influence of forming process on three-dimensional morphology of $\mathrm{TiB}_{2}$ particles in Al-Ti-B alloys. Transactions of Nonferrous Metals Society of China, 2012, 22(3): 564-570.

[14] Huang $Y C$, Shao H B, Xiao $Z B$, et al. First principle study of $\mathrm{AlB}_{2}, \mathrm{TiB}_{2}$ and $\mathrm{TiAl}_{3}$ in Al-Ti-B alloy. The Chinese Journal of Nonferrous Metals, 2018, 28(8): 1491-1498. (In Chinese)

[15] Jia $Y$ W, Wang $S B$, Huang $H$ J, et al. In situ observation of the $\mathrm{Zr}$ poisoning effect in Al alloys inoculated by Al-Ti-B. Metallurgical and Materials Transactions A, 2018, 49(21): 4771-4784.

[16] Julius C. Schuster Martin Palm. Reassessment of the binary aluminum-titanium phase diagram. Journal Phase Equilibria and Diffusion, 2006, 27(3): 252-256.

[17] Wei W, Mao R Y, Wei K X, et al. Effect of equal channel angular pressing on microstructure and grain refining performance of Al-5\%Ti master alloy. Materials Science \& Engineering A, 2013 564: 92-96.

[18] Wang Z J, Si N C. Synthesis and refinement performance of the novel Al-Ti-B-RE master alloy grain refiner. Rare Metal Materials and Engineering, 2015, 44(12): 2970-2975.

[19] Zhang $L L$, Jiang $H X$, Zhao J Z, et al. A new understanding toward effect of solute $\mathrm{Ti}$ on grain refinement of aluminum by Al-Ti-B master alloy: Kinetic behaviors of $\mathrm{TiB}_{2}$ particles and effect of solute Ti. Acta Metallurgica Sinica, 2017, 53(9): 10901098. (In Chinese) 